\title{
Child Safety, Absolute Risk, and the Prevention Paradox
}

Peter H. Schwartz

March 2012

\section{$\underline{\text { Hastings Center Report }}$}

\section{Introduction:}

Imagine you fly home from vacation with your one-and-a-half year old son who is traveling for free as a "lap child." In the airport parking lot, you put him into his forward-facing car seat, where he sits much more contentedly than when he was in the rear-facing one, until his first birthday. After he falls asleep on the way home, you transfer him to his crib without waking him, aided by first lowering the side rail.

Many parts of this idyllic parenting picture are deemed unacceptably risky according to recent child safety proposals. First, the National Transportation Safety Board (NTSB) has recommended that children under two years-old should be required to have their own plane ticket and ride in a car seat. ${ }^{1}$ Second, the American Academy of Pediatrics (AAP) and National Highway Traffic Safety Administration (NHTSA) have recommended that children should travel in rear-facing car seats until age two, rather than changing to a front-facing car seat at their first birthday. ${ }^{2,3}$ Finally, the Consumer Product Safety Commission (CPSC) has banned drop-side cribs. ${ }^{4}$

While these proposals all aim to improve child safety, their possible impact is unclear since there's been so little discussion of the amount of absolute risk and risk reduction involved in each. And while precise figures are lacking, rough estimates indicate that the magnitudes are quite small. I will argue that this risk and benefit data raises important questions about the proposals, including whether parents might reasonably believe that the small absolute risk reduction offered by the proposed changes does not justify the attendant burdens. This possibility - termed the "prevention paradox" in other contexts - highlights ethical and theoretical challenges in this area of public health.

\section{What are the numbers?}

$\underline{\text { Rear-facing and forward-facing car seats: }}$ 
Advocates of rear-facing car seats (RFCS) for children until age 2 emphasize that they protect children more effectively than do front-facing car seats (FFCS). ${ }^{5}$ Analysis of crash data suggests that while FFCS prevent $69 \%$ of the serious injuries and deaths that children this age would suffer when riding unrestrained, RFCS prevent $86 \% .^{6}$ In other words, RFCS provide a $25 \%$ relative risk reduction compared to FFCS (calculated by: $86 \%$ minus $69 \%$, and this amount then divided by $86 \%$ ).

That seems impressive, but now consider the absolute risk involved. ${ }^{\text {a }}$ In 2007, according to a national database, 44 children between ages 1 and 2 who were riding in a car seat died in motor vehicle crashes. ${ }^{7}$ The data does not specify whether these children were riding in front- or rear-facing seats; to produce the highest reasonable estimate for risk to children riding in FFCS, I will assume they all were riding forward facing.

But that's just the numerator for absolute risk, and there's no clear way to settle on the denominator, that is, the number of children ages 1-2 who rode in a FFCS in 2007. To estimate that number, it may be best to assume that almost all children in this age group (approximately 4 million) rode in a car at some point that year. A study also done in 2007 found that $73 \%$ of children ages 1-3 years old who were traveling in a car were in a FFCS (just 3\% were in a RFCS $) .9$ Therefore, a reasonable estimate is that $73 \%$ of four million children ages $1-2$ rode in a FFCS in 2007, for a total of 2,920,000.

According to these calculations, the risk of mortality for children ages 1-2 travelling in a FFCS in 2007 was 44 divided by 2,920,000, or 1.5 per 100,000. If RFCS are $25 \%$ more effective than FFCS, that means that switching would save one-quarter of these, or 3.8 children per million children per year. ${ }^{\mathrm{b}}$

Drop side crib mortality estimates:

\footnotetext{
${ }^{a}$ Absolute risk is calculated by dividing the number of individuals who experience an undesirable outcome by the total number of individuals exposed to the situation or risk factor. b Certainly, this estimate could be refined - but the general magnitude is not likely to change much. For instance, the US Census Bureau estimates that $8.8 \%$ of families in the United States in 2007 did not have a car. ${ }^{8}$ While it would be reasonable to assume that even children in these families traveled in a car at some point during the year, assuming that none of them did would result in only a small change in the estimated risk of mortality: resulting in a risk of approximately 1.6 or 1.7 per 100,000 rather than 1.5 per 100,000 children per year.
} 
The CPSC and many news articles emphasize that at least 32 and as many as 46 children died in drop-side-crib accidents from 2000 to $2010 .{ }^{10}$ But, again, this is just the numerator in a calculation of risk, and estimating the denominator, that is, the number of children who slept in drop-side cribs during this time period, is difficult.

We do know that drop side cribs were quite popular starting in the 1990's, eventually constituting up to $50 \%$ of the market, though that dropped off to $18 \%$ by $2009 .{ }^{c}$ Since there are roughly 4 million children born in the United States each year, resulting in 40 million from 20002010, then even if just $10 \%$ of those children slept in drop side cribs, the risk would be 32 to 46 per 4,000,000, or about 1 per 100,000. That's about the best we can do in estimating the mortality risk for children sleeping in drop side cribs.

These estimate of risk of FFCS and drop side cribs are just for mortality, rather than for morbidity. This reflects the fact that information available about injuries is even more incomplete than for deaths.

\section{Lap children:}

Things are even worse for making an estimate about the risk to lap children. Nobody knows how many lap children are injured or killed on airplanes, much less the total number who travel this way. In its recommendation, the NTSB instead utilizes general reasoning and anecdotal evidence, such as cases where children who were injured might have been protected by being in a car seat. ${ }^{1}$

\section{Importance of the numbers:}

The difficulty of making estimates about absolute risk and risk reduction for the relevant situations - and the need to rely on speculative assumptions - highlights the limitations of what is currently known. This could be an immediate red flag for the proposals: One could conclude that we need to gather more data before putting any of these recommendations into place.

At the same time, one could argue that we cannot wait to move forward with proposals that could save children's lives. The first thing to note about such a response is that it violates the usual ways in which the government considers regulations aimed at reducing risk. For

\footnotetext{
${ }^{\mathrm{c}}$ Personal communication, Mike Dwyer, Executive Director, Juvenile Products Manufacturers Association (JPMA).
} 
example, federal agencies will often consider regulating a pollutant only if it poses greater than de minimis risk, which is roughly a 1 in 10,000 risk of mortality to exposed individuals. ${ }^{11}$ Of note, the risks estimated above for a child riding in a FFCS and for sleeping in a drop side crib are well below that threshold.

In addition, data about absolute risk and risk reduction are necessary to estimate the costper-life-saved, a standard measure in this area. For example, the Transportation Department, Environmental Protection Agency, and Food and Drug Administration have recently rejected safety regulations based on their costing more than about $\$ 6-9$ million per life saved. ${ }^{12}$

Remember that these child safety proposals have costs. Although some parents have a car seat for their 1-year-old that can be attached forwards or backwards, other families would need to buy a different seat. To comply with the ban on drop-side cribs, many parents as well as daycare centers and hotels must buy new cribs. And the cost to parents of eliminating the lap child rule goes without saying.

\section{Countervailing risks and individual variation:}

Further, for the proposals where one can estimate the absolute risk reduction, the small magnitude increases the possibility that countervailing risks will outweigh any benefits. A screaming child - unhappy to be sitting backwards in a RFCS - may worsen a parent's driving. And if a fixed-sided crib means that it is more difficult to place the child down gently or pat him to sleep, parents may choose to put the child on a bed instead, with no side rails. Or they may raise the level of the mattress in the crib, increasing the chance of the child's climbing out and falling, the most common cause of crib injuries. ${ }^{13}$ The Federal Aviation Administration has stuck with the lap child rule in part due to concern that eliminating it might lead parents to drive rather than buy an extra plane ticket, exposing children to the higher risks of motor vehicle travel. ${ }^{1}$

These possible countervailing risks, coupled with the small magnitude of the absolute risk reduction involved, also increase the importance of individual variation. Children in a RFCS may complain more or less vociferously, and parents may be more or less distracted, resulting in varying effects on driving safety. For sleeping children, some parents use audio or even video monitors, or have newer or better constructed cribs, reducing the risk posed by drop sides. 
As evidence-based medicine emphasizes for any intervention (be it a pill, device, or procedure), only careful research can determine whether an expected benefit will be achieved and how effects may differ among groups. So, while lowering blood sugars in diabetics may reduce long-term cardiovascular risk, the benefit can be outweighed for certain patients by the risk of severe hypoglycemia. ${ }^{14}$ Of course it is incredibly difficult to carry out a perfect test of a pill or procedure, and even more challenging for proposals like eliminating drop side cribs or ending the lap child rule. Plenty of medical interventions become standard without adequate testing, but of course that doesn't make it right to take a similar approach with child safety proposals.

\section{The Prevention Paradox:}

Finally, one might wonder whether the small magnitude of risk reduction promised by each proposal would be seen by parents as justifying the attendant burdens. It seems that a parent could reasonably decide that the risks of traveling with a lap child or using a FFCS or drop side crib are outweighed by the comfort and ease provided.

This possibility raises the prevention paradox, described by Geoffrey Rose 30 years ago for cardiovascular disease: Preventive efforts that can save lives at a population level may not seem to be worth it at the individual level. ${ }^{15}$ For example, even if eliminating a beloved food from a country's diet would save 20 people per year from dying of heart attacks, if the individual risk reduction is just 1 in 100,000, the sacrifice may not be worth it to most people.

While the prevention paradox has not been discussed in the area of child safety, it certainly applies to these proposals. The simplest response, in this or other areas, would be to conclude that if a change that would reduce mortality in the population could be reasonably rejected by at least some fully informed individuals, then a regulation requiring the change is inappropriate. In such cases, it might seem that a recommendation would be more ethically acceptable.

But how strong a recommendation? The proposal to keep children in a RFCS from ages 1-2 is just a recommendation, but the AAP and the NHTSA push quite hard, implying that it is

the only responsible choice for parents. ${ }^{16}$ One could argue that such a recommendation should be weaker, acknowledging that one could reasonably choose the ease over the risk reduction. At the same time, such caveats would muddy the message and possibly lead parents to favor the 
status quo over the available risk reduction in an irrational or uninformed way. The prevention paradox is truly paradoxical: there is no simple answer for how to respond.

The puzzle can also be analyzed within utilitarianism, the dominant theoretical model for public policy. From this perspective, a parent who rationally rejects a recommendation such as switching from FFCS to RFCS is judging that the high probability of a small decrement in utility (stemming from the child's unhappiness facing backwards) is larger, in terms of expected utility, than the extremely small probability of a great loss of utility (due to a preventable injury or death). If that judgment is correct for each possibly affected parent, then making the change population-wide would yield a net loss in expected utility.

A utilitarian defense of these proposals might reject simply summing up the small decrement in utility for many parents and children: various puzzles for utilitarianism can be addressed by aggregating small changes in utility in other ways (such as discounting changes that fall below a certain threshold). ${ }^{17}$ Or one could propose considering utility effects just from health outcomes, ignoring utility changes stemming from factors such as ease of traveling. While that approach might be supported by claiming that public health is in the business of improving health, not ease of parenting, it willfully disregards issues that could be extremely important to a majority of individuals.

However you slice it, the prevention paradox highlights the complexity of the ethics involved in making public health policy in this area, perhaps most importantly by demonstrating how population- and individual-level interests may conflict.

\section{Conclusion:}

In summary, failing to consider absolute risks and absolute risk reduction is a serious mistake when evaluating child safety proposals (indeed, any safety proposal). If making reliable estimates is difficult, that should be acknowledged and discussed. When available, absolute risk reduction should be used to evaluate the possible impact of countervailing risks, individual variation, and the burden on parents. Perhaps most importantly, facing these issues blocks the too-easy assumption that recommendations that may save some children's lives are "no brainers," or that failure to follow such recommendations is always poor parenting or irrational.

Better data is available and discussed for some other child safety initiatives, such as the campaign to convince parents to place infants supine (on their back) to sleep. The "Back to 
Sleep" movement, combined with other safe-sleeping recommendations, may have been responsible for reducing the risk of Sudden Infant Death Syndrome (SIDS) from 120 per 100,000 to 56 per 100,000, a risk reduction in mortality of 64 per 100,000. ${ }^{18}$ That's more than 60 times the risk reduction calculated above for eliminating drop side cribs and 150 times the risk reduction of switching children ages 1-2 from a FFCS to a RFCS. The magnitude of risk reduction doesn't completely eliminate concerns about individual variation or even the prevention paradox, but it provides a useful way to approach such issues and to evaluate and compare the impact of possible initiatives.

\section{Acknowledgments:}

Thanks to Mike Dwyer, Chris Feudtner, Eric Meslin, Paul Muriello, Greg Sachs, Jere Odell, and Suad Wanna-Nakamura for discussion and assistance. Dr. Schwartz is supported in part by a Cancer Control Career Development Award for Primary Care Physicians from the American Cancer Society (CCCDA-10-085-01) and by the Predictive Health Ethics Research Project, funded by the Richard M. Fairbanks Foundation.

\section{References:}

1. National Transportation Safety Board (NTSB). "Safety recommendation." 2010. Available at http://www.ntsb.gov/doclib/recletters/2010/A-10-121-123.pdf. Accessed November 20, 2011.

2. D. R. Durbin. "Policy statement: Child passenger safety." Pediatrics 127, no. 4 (2011): 78893.

3. National Highway Traffic Safety Administration (NHSTA). "Car seat recommendations for children." Available at: http://www.nhtsa.gov/DOT/NHTSA/Traffic\%20Injury\%20Control/Articles/Associated\%20F iles/4StepsFlyer.pdf. Accessed November 20, 2011.

4. U.S. Consumer Product Safety Commission (CPSC). "CPSC approves strong new crib safety standards to ensure a safe sleep for babies and toddlers." Available at: http://www.cpsc.gov/cpscpub/prerel/prhtml11/11074.html. Accessed November 20, 2011.

5. D. R. Durbin. "Technical report: Child passenger safety." Pediatrics 127, no. 4 (2011): e1050-66. 
6. B. Henary, C. P. Sherwood, J. R. Crandall, R. W. Kent, F. E. Vaca, K. B. Arbogast, and M. J. Bull. "Car safety seats for children: Rear facing for best protection." Inj Prev 13, no. 6 (2007): 398-402.

7. National Highway Transportation Safety Association (NHTSA). "Fatality analysis reporting system (FARS)." Available at: http://wwwfars.nhtsa.dot.gov/QueryTool/QuerySection/SelectYear.aspx. Accessed November 20, 2011.

8. U.S. Census Bureau. "Selected housing characteristics: 2007." In American Community Survey, Available at: http://factfinder.census.gov/servlet/ADPTable? bm=y\&geo_id=01000US\&-qr_name=ACS_2009_5YR_G00_DP5YR4\&-ds_name=\&-_lang=en \&redoLog=false \&-format $=$ Accessed November 20, 2011.

9. National Highway Traffic Safety Administration (NHTSA). "Research note: Child restraint use in 2008 - use of correct restraint types." Available at http://wwwnrd.nhtsa.dot.gov/Pubs/811132.PDF. Accessed November 20, 2011

10. U.S. Consumer Product Safety Commission (CPSC). "CSPC issues warning on drop-side cribs." Available at http://www.cpsc.gov/cpscpub/prerel/prhtml10/10225.html. Accessed November 20, 2011.

11. Curtis C. Travis, Samantha A. Richter, Edmund A. C. Crouch, Richard Wilson, and Ernest D. Klema. "Cancer risk management: A review of 132 federal regulatory decisions." Environ. Sci. Technol., Vol. 21. No. 5. 198 21, no. 5 (1987): 415-20.

12. Binyamin Appelbaum. "As U.S. agencies put more value on a life, businesses fret." New York Times, February 17, 20112011.

13. E. S. Yeh, L. M. Rochette, L. B. McKenzie, and G. A. Smith. "Injuries associated with cribs, playpens, and bassinets among young children in the US, 1990-2008." Pediatrics 127, no. 3 (2011): 479-86.

14. Victor M. Montori, and Merce` Fernandez-Balsells. "Glycemic control in type 2 diabetes: Time for an evidence-based about-face?" Annals of Internal Medicine 150, no. 11 (2009): 803-08.

15. G. Rose. "Strategy of prevention: Lessons from cardiovascular disease." British Medical Journal Clinical Research Ed 282, no. 6279 (1981): 1847-51. 
16. American Academy of Pediatrics. "Car safety seats: Information for families for 2011." Availale at: http://www.healthychildren.org/English/safety-prevention/on-the-go/Pages/CarSafety-Seats-Information-for-Families.aspx. Accessed November 20, 2011.

17. D. W. Brock. "Ethical issues in the use of cost-effectiveness analysis for the prioritization of health care resources." In Making choices in health: Who guide to cost-effectiveness analysis, edited by R. Baltussen T. Tan-Torres Edejer, T. Adam, R. Hutubessy, A. Achary, D.B. Evans, and C.J.L. Murray, 289-312. Geneva: World Health Organization, 1993.

18. R. Y. Moon, American Academy of Pediatrics, Task Force on Sudden Infant Death Syndrome. "Technical report-SIDS and other sleep-related infant deaths: expansion of recommendations for a safe infant sleeping environment." Pediatrics. 2011:128; e1341; available online at http://pediatrics.aappublications.org/content/128/5/e1341.full.html 